Reviews in Digital Humanities • Vol. 2, No. 12

\title{
Editors' Note: December 2021
}

Roopika Risam ${ }^{1}$, Jennifer Guiliano ${ }^{2}$

${ }^{1}$ Salem State University, ${ }^{2}$ IUPUI

Published on: Dec 13, 2021

DOI: $10.21428 / 3 e 88 f 64 f . f c c 8 b 9 e d$

License: Creative Commons Attribution 4.0 International License (CC-BY 4.0). 


\section{Editors' Note}

\section{Roopika Risam and Jennifer Guiliano}

Welcome to the December 2021 issue of Reviews in Digital Humanities! This month marks the conclusion of two years of issues featuring peer reviews of digital scholarship.

While our two years of publication have coincided with the Covid-19 pandemic, we have worked to publish regular issues and to keep our review workflow moving. Here are a few highlights:

- We secured \$66,000 in funding from the Andrew W. Mellon Foundation to support our journal pilot, including long-term planning for the financial viability of the journal.

- Funding from Mellon allowed us to hire editorial assistants Evan Miller and Miranda Hughes, giving students at Salem State University the opportunity to gain valuable experience in publishing.

- We have published 21 issues, which includes monthly issues in 2021, featuring 80 projects.

- Special issues in journal have highlighted the work of scholarly communities that are often overlooked in digital humanities: Borderlands Digital Humanities, Jewish Digital Humanities, Latinx Digital Humanities, and Sound Studies.

- Reviews has been used in courses, both as assigned reading, inspiration for assignments, and a "Reviews in Digital Humanities in the Classroom" special issue edited by Tanya Clement.

- Our project registry now allows users to find projects by name, time period, field of study, and topic or method.

- We have successfully arranged for timely peer reviews of projects for tenure and promotion cases.

The success of the journal has only been possible through the collective work of digital humanities communities. Thank you to the project directors, reviewers, and special issue editors who have contributed to the journal, as well as the Mellon Foundation and Catherine Ahearn at the Knowledge Futures Group for their support. We are looking forward to continuing our work on the journal in 2022. 
In this month's issue, we feature projects that showcase digital humanities interventions over a range of time periods, genres, and traditions:

- Dante Visualised, a text analysis tool for data visualization that examines Dante's Divine Comedy as a use case, developed by Ginestra Ferraro and reviewed by Crystal Hall;

- Furnace and Fugue, a digital edition of Michael Maier's Atalantia fugiens, directed by Allison Levy and reviewed by Alicja Bielak;

- ArchivalGossip, a website and database focusing on the role of gossip in the 19th century, directed by Katrin Horn and reviewed by Molly Mann; and

- The East End Digital Library, a project that makes 19th-century archives of London's East End available to the public, directed by Heidi Kaufman and reviewed by Abigail Droge.

All of the projects are, in their own ways, models for digital humanities practice that could be adapted for multiple texts and contexts. While Dante Visualised uses the Divine Comedy as a corpus for its visualization tool, the tool itself has wider applicability to other Italian texts of that era and to other literary traditions in other periods. Furnace and Fugue's innovative blend of word, image, and sound demonstrates how multimodal projects can offer users new ways to engage with texts through its inventive approach to the digital edition. ArchivalGossip's focus on 19thcentury gossip prompts scholars to take gossip seriously as an object of study in feminist, gender, and sexuality studies through digital methods. Finally, the East End Digital Library offers an important example of how digital projects can redress gaps and omissions in the digital cultural record as it shifts attention in that region of London in the 19th century away from Jack the Ripper and towards literary and cultural production of Jewish families.

Want to be part of Reviews? You can submit a project for review, nominate a project you admire, volunteer for our reviewer pool, and tell your colleagues and students about the journal.

Questions? Thoughts? Concerns? Contact the editors, Jennifer Guiliano and Roopika Risam, by email or through the Twitter hashtag \#ReviewsInDH. 